\title{
HOSPITAL BASED MATERNITY CARE IN GHANA - FINDINGS OF A CONFIDENTIAL ENQUIRY INTO MATERNAL DEATHS
}

\author{
JANET ANSONG-TORNUI, "MARGARET ARMAR-KLEMESU, DANIEL ARHINFUL, \\ SUZANNE PENFOLD ${ }^{1}$ and JULIA HUSSEIN ${ }^{1}$ \\ Immpact, Noguchi Memorial Institute for Medical Research, University of Ghana, Legon, Ghana \\ and ${ }^{1}$ Immpact, University of Aberdeen, Health Sciences Building, Foresterhill Campus, Aberdeen, \\ UK AB25 2ZD
}

\begin{abstract}
SUMMARY
Background: In Ghana, a universal free delivery policy was implemented to improve access to delivery care in health facilities, thereby improving access to skilled attendance and reducing maternal mortality.

Objective: A confidential enquiry was conducted to ascertain if changes had occurred in the care provided by reviewing the care given to a sample of maternal deaths before and after introduction of the policy.

Method: Twenty women who died as a result of pregnancy-related complications (maternal deaths) in selected hospitals in two regions were assessed by a clinical panel, guided by a maternal death assessment form. Unlike the traditional confidential enquiry process, both adverse and favourable factors were identified.

Findings: Clinical care provided before and after the introduction of the fee exemption policy did not change, though women with complications were arriving in hospital earlier after the introduction of the policy. On admission, however, they received very poor care and this, the clinical panel deduced could have resulted in many avoidable deaths; as was the case before the implementation of the policy. Consumables, basic equipment and midwifery staff for providing comprehensive emergency obstetric care were however found to be usually available.

Conclusion: Our findings suggest that the already poor delivery care services women received remained unchanged after introduction of the policy.
\end{abstract}

Keywords: Hospital, maternity care, confidential enquiry, maternal deaths.

\section{INTRODUCTION}

Ghana has persistent unacceptably high maternal mortality ratios most recently estimated to be 540 per 100,000 live births. ${ }^{1}$ The levels of antenatal care with a health professional reached $92 \%$ in
2003, although the increase in demand for delivery care with a health professional has been much slower, from $41 \%$ to only $47 \%$ of deliveries conducted by health professionals over the 15 years before $2003 .^{2,3}$ Service use is unequally distributed between different socio-economic groups. Analysis of the 2003 Demographic and Health Survey ${ }^{2}$ data on delivery service utilisation by poverty level demonstrates that there is a greater than fourfold difference in uptake of delivery care with a health professional between the poorest and richest quintiles. Documented barriers to the use of professional skilled care include user fees ${ }^{4}$, poor confidence in the services provided ${ }^{5}$ and bad attitudes of health professionals ${ }^{6}$.

In 2003, a policy was implemented in Ghana that aimed to improve access to health services for the poor and the vulnerable, by putting into place universal exemption from payment of user fees for all delivery care. It was expected that the policy would remove financial barriers to accessing these services, allow an increase in professionally attended deliveries and thus a reduction in maternal and perinatal mortality. The policy was implemented firstly in the four most disadvantaged regions in 2003 and then extended to cover all regions in the country in 2005 .

Tracing adverse and favourable events in pregnancy care (TRACE) was a sub study which was conducted within the larger evaluation of the policy of fee exemption for delivery care. Other components include assessments of the degree and means of implementation of the fee exemption policy, quality of care (clinical as well as social perspectives), quantification of institutional maternal deaths and various forms of economic analysis. This qualitative in depth review of maternal deaths in health facilities was intended to supplement the quantitative study on institutional maternal deaths as well as provide an alternative point of reference

* Author for correspondence

MArmar-Klemesu@noguchi.mimcom.net 
to compare with the findings from the quantitative measures of quality of care.

The TRACE study objectives were to describe the occurrence of favourable and adverse events in the provision of care in maternal deaths that occurred in the study areas and to compare these events before and after the introduction of delivery fee exemption.

\section{METHODS}

The study was conducted in the Volta and Central regions of Ghana. Central region was one of the first regions to introduce the policy in September 2003. In April 2005, the policy was extended to all regions in Ghana, including Volta. The two regions comprise districts that have similar profiles and can be matched on the basis of presence of a hospital, poverty status, size of the population and urban profile. The study was conducted from January to July 2006.

The study was based on a modification of confidential inquiry into maternal deaths. The confidential enquiry method ${ }^{7}$ is based on adverse events related to maternal deaths, thus identifying "substandard care". The approach used in the TRACE study was a modification of the conventional method and included favourable factors or events. The identification of favourable factors was expected to reveal the strengths of the health system and allow recommendations to capitalize and build on these.

\section{Study design}

The study was a pre- post-intervention design used to describe and compare events at delivery before and after the introduction of universal fee exemption.

Ethical approval was obtained from the Noguchi Memorial Institute for Medical Research (NMIMR). Permission to undertake the study was obtained from the regional and district health authorities in the two regions.

\section{Study population}

The study population consisted of cases of delivery-related hospital maternal deaths in Central and Volta regions. The sample included deaths that occurred before and after fee exemption in each of the two regions. Ten cases each were selected from each region, and of the ten, five were attended to before and the other five after fee exemption was introduced. Cases with a range of different direct obstetric complications (haemorrhage, eclamp- sia/pre-eclampsia, obstructed labour, sepsis) as well as indirect obstetric complications were included in the sample. The sample size was restricted by feasibility and time issues. Cases of ectopic pregnancy, abortion, and complications in early pregnancy (less than 28 weeks gestation) were excluded.

\section{Maternal death assessment forms}

The basic structure for the detection of opportunities and defects in health care was predetermined using the "maternal death assessment form". Assessment was confidential, anonymised and based on hospital records including clinical case notes, nursing notes, partographs, laboratory forms and billing accounts. The form was developed from review of pre-existing maternal death assessment forms ${ }^{7,8}$ and was based mostly on the South African version ${ }^{7}$ which is structured into four main areas concerning the woman/patient and her community, administrative or health system factors, the clinical care provided to each individual case and the degree of availability of information.

\section{Assessment panel ${ }^{\dagger}$}

An eight-member panel comprising specialists in obstetrics, midwifery, anaesthesiology, internal medicine, pathology and public health was set up. Panel members individually reviewed the clinical case records and identified adverse and favourable events as well as errors or omissions in the provision of care. Their findings for each case were recorded on the "maternal death assessment form". The panel met monthly over a period of six months to review their assessment and one overall agreed assessment form was completed for each case. The individual and panel forms were collected at the end of each panel meeting.

\section{Data collection}

The primary source of case identification was the Admissions \& Discharges Book with crossreference to the Delivery Register. Case notes were retrieved from the Medical Records office. Any associated information such as maternal death audit and post mortem reports were included if available. Photocopies of the records were made and fully anonymised. Panel members were blinded to whether the cases belonged to the "pre" or "post" intervention group.

\footnotetext{
${ }^{\dagger}$ P. Antwi, M-M. Arthur-Mensah, E. Asiedu, S. Deganus, F. Komla Boni, K. Nkyekyer, F. Ofei and Y. Tettey.
} 


\section{Data analysis}

Analysis was done manually by two researchers. A summary of each case was constructed from the original case records and panel assessment forms by the first researcher. The details were independently cross-checked by the second researcher. A review of all the individual and panel maternal death assessment forms was then undertaken. Any differences between the two types of forms were identified and cross-checked with the case records to identify the correct details. Additional information from individual forms that were not represented in the overall form was included. This information was summarised in four matrices, each comprising 5 cases "before" and "after" the intervention, and in Central and Volta regions. The matrices organised the panel findings in relation to four themes - patient oriented factors, health system factors, care provided and availability of information.

Cut off points were identified according to the date death occurred in relation to the start of implementation of the exemption policy. For Central region the start of fee exemption was set at $1^{\text {st }}$ January 2004; and cases were selected 24 months before and after the start point. In the Volta region the starting point for fee exemption was $1^{\text {st }}$ April 2005 and therefore cases were selected 12 months before and after this date.

Because health workers do not record their rank, and as a result of the anonymisation process it was not always possible to distinguish between different types of health professionals in the case notes. The general premise used in the analysis was that nursing or midwifery staff would enter their notes in designated sections of the case records (nursing notes, monitoring charts for vital signs) and doctors (and medical assistants) would enter information in the medical notes, anaesthetic records and operating notes.

\section{RESULTS}

A total of 20 cases of maternal deaths were studied out of which eighteen cases were intrapartum or postpartum deaths that occurred in a hospital. Two women died undelivered - one was at term but not in labour and the other was possibly in very early labour. Table 1provides the number of cases and types of hospitals from which they were selected for the panel review.

\section{Profile of cases (Woman related factors)}

The women's ages ranged between 20 and 42 years. The primary causes of death were post par- tum haemorrhage (PPH, 6/20 cases), puerperal sepsis (PS, 5/20 cases), anaesthetic or medical causes $(4 / 20)$, eclampsia $(3 / 20)$, one uterine rupture and one case of antenatal sepsis. Most of the women suffered more than one major complication.

Table 1 Cases selected

\begin{tabular}{lll}
\hline \multicolumn{1}{c}{ Intervention } & \multicolumn{1}{c}{ Central } & \multicolumn{1}{c}{ Volta } \\
\hline $\begin{array}{l}\text { Pre fee exemp- } \\
\text { tion }\end{array}$ & $\begin{array}{l}5 \text { cases selected } \\
\text { from 3 district } \\
\text { hospitals and } \\
\text { one regional } \\
\text { hospital }\end{array}$ & $\begin{array}{l}\text { 5 cases se- } \\
\text { lected from 3 } \\
\text { district hospi- } \\
\text { tals and one } \\
\text { regional hos- } \\
\text { pital }\end{array}$ \\
$\begin{array}{l}\text { Post fee ex- } \\
\text { emption }\end{array}$ & $\begin{array}{l}5 \text { cases selected } \\
\text { from 3 district } \\
\text { hospitals and } \\
\text { one regional } \\
\text { hospital }\end{array}$ & $\begin{array}{l}\text { lected from 4 } \\
\text { district hospi- } \\
\text { tals }\end{array}$ \\
& & \\
\hline
\end{tabular}

The majority of cases (15/20) originated from home while the remainder were referrals from health centres (2), a Traditional Birth Attendant, (1), and other hospitals (2). Most deaths occurred within 24 hours of admission. About half the cases were either admitted or died in the early hours of the morning or late at night. Ten of the cases were delivered normally, while eight (8) had an operative delivery by Caesarean Section (CS) or another uterine procedure and the remaining two cases were not delivered at all before they died. Most $(14 / 20)$ of the deliveries occurred in hospital. The time from delivery to death ranged from 1 hour to 14 days. Half the number of babies was recorded as being born alive, although records on the condition of the babies at delivery were inadequate.

Most of the twenty women were reported to be in some form of employment, and in one or two cases, were accompanied by family. Information on educational levels were available in only a few cases, marital status in a few others, but otherwise, information on the woman's, family and community circumstances was not recorded by health staff as required. An examination of the characteristics of these women revealed no major differences in their profiles when women who were admitted before the introduction of the policy were compared with those admitted after fee exemption in the two regions.

\section{Community related factors}

There was one example of a possibly harmful traditional practice of herbal drug use in a previous 
CS who delivered at home. Another case of delay in seeking care was seen in a woman with "profuse bleeding after home delivery". She was admitted two weeks after delivery "in stable condition". In both instances, although the neglect at community level and delayed seeking of care could have contributed to patients' death, the panel found that the eventual cause of death was more directly attributable to sub-standard care received in hospital. A patient with PPH for example was transfused after admission but her death four days after admission was related to iatrogenic fluid overload and insufficient treatment of sepsis.

Six deaths were in patients admitted in what appeared to be a serious condition and subsequently died from that complication. In all the other deaths, the patient died from another complication (for example severe pregnancy-induced hypertension (PIH) aggravating a PPH which caused death) or was not in serious condition at all on admission. These six deaths all occurred in the time before fee exemption - two in Central Region and four in Volta Region. Only one case of this nature was identified after fees were lifted i.e. a woman who delayed in reporting when her condition was deteriorating.

\section{Care during an emergency situation}

The key finding of this study was that levels of care for complications and in acute emergency situations were sub-standard. Levels of care nonetheless, did not deteriorate as a result of the implementation of the fee exemption policy given that the expected increases in client numbers were not matched by increases in available resources.

General clinical management - The care provided by doctors was assessed consistently as below expectation, and this level of care was observed before and after introduction of the policy. In the estimation of the panel of experts poor case management, bad decision making and unacceptable attitude of doctors was common. Take for example the case of a patient who had a normal labour and delivery, followed by postpartum eclampsia: panel members were of the view that there was a delayed comprehensive response to this life threatening complication by the medical staff. And in a second case, the panel's inference from the case review was that the doctor's decision to discharge a patient upon the patient's request was inconsistent with good obstetric practice. They thought that the doctor did not appreciate the importance of clinical features such as fever, jaundice and hepatomegaly which were obvious during the patient's first admission and was commented on by the midwife.

The panel, on the other hand, assessed midwifery care as superior to that of doctors, because there were many more examples of acceptable midwifery practice in terms of management and communication, initial diagnostic assessments, and recognition of specific danger signs and symptoms including jaundice, pyrexia and foetal wellbeing. Admittedly, examples of substandard care by midwives were also identified; especially, poor monitoring of vital signs and fluid balance.

Resuscitation - Panel members agreed that resuscitation was insufficiently aggressive and not competently managed. In one patient, there was a lack of recognition of the cause of the severe anaemia and shock, which the review panel deduced was most probably due to a retained placenta. There was, nonetheless, a delay in removal of the placenta which was not initiated on time before the patient's demise as well as inadequacy of the resuscitation process. ${ }^{9}$ Two other cases reviewed were assessed by the panel as follows:

"There was poor management at all stages of labour...poor initial and continuous monitoring...especially by the doctor...complications of bleeding, sepsis and PIH were poorly recognised and managed [including] unorthodox management of bleeding using ice packs... [and no administration of syntocinon]. The doctor did not make a tentative diagnosis and did not take charge of the management..."9

"She made poor progress in labour over the next $46 \mathrm{hrs}$ but no definitive action was taken despite poor progress. Emergency CS was carried out presumably without adequate anaesthesia care and without proper anticipation of the possible complication of uterine rupture. The surgeon did not appear to be sufficiently competent to handle the complication of uterine rupture encountered involving the left uterine artery with profuse bleeding. The patient died from haemorrhagic shock after the operation without adequate resuscitation measures and monitoring",

Additionally, doctors paid infrequent visits to their patients who had serious complications or had undergone surgical operative procedures. Of the 20 deaths, only 5 cases had a doctor attending (despite being informed) in the time leading up to, and during the final critical events prior to death. 
Furthermore, hydrocortisone was administered parenterally as a last resort to save patients' life. This was the most common example of unnecessary medical treatment. Eleven (11) of the 20 cases were given hydrocortisone for the purposes of acute resuscitation without a specific indication.

\section{Health system factors}

Transport/access/referral - referral was generally "favourable" and did not contribute to the deaths. There was no indication in case records of any undue time delays or difficulties accessing services. The origin of the patient was usually available from the records, but there were no marked differences in referral pattern before or after the policy. Of the referred cases from a Traditional Birth Attendant (TBA) or another health facility, there appeared to be minimal time delays, with referral times ranging between 30 minutes to 3 hours. The woman who took three hours to arrive from another facility was in stable condition. Suboptimal referral included the absence of a health professional to accompany the patient and inadequate details in referral letters.

Physical medical facilities (infrastructure, equipment, consumables) - a clear finding in all the cases was the availability of comprehensive emergency obstetric care facilities. Consistently, laboratory tests as well as blood transfusions had been requested. In only one of the three cases where blood was not available could the acute lack of blood be linked to patient's death. Most drugs had been prescribed as appropriate and appeared to have been administered correctly. Nevertheless, it was also found that of seven cases of fulminating pre-eclampsia or eclampsia, magnesium sulphate was administered in only three cases. And only in one case was it noted that magnesium sulphate was considered as the most appropriate treatment, but was not available.

Health personnel availability -The health personnel factors related to the health system were subdivided into three areas for the panel's assessment - availability, appropriate training and communication. There were no differences before and after implementation of the policy in any of these areas. In general, the availability of a midwife or nurse seemed to be good. Patients were invariably assessed by a health professional, usually a midwife, on arrival. Doctors were less available. The non-availability of doctors was usually not explained, except in one case after the policy was in place. It was recorded in the nursing notes the doctor said he was tired and exhausted 9 .

\section{Availability of information}

Information provided in the clinical case notes was assessed as grossly inadequate by the review panel. There was insufficient and poor quality recording of clinical events. It would be generally expected that if a procedure is unusually complicated, recording of the events would be more detailed. In an instance, the operative procedure conducted comprised repair of a uterine scar rupture with extension into the uterine artery. The operative notes were so scanty that the panel suspected that the doctor was completely out of his depth.

Partographs were only found in five (5) out of 13 case records where labour had taken place. Of the five, only two were completed to the panel's satisfaction. Only one maternal death audit record was completed out of the 20 deaths reviewed. Post mortems were usually not done (sometimes at the request of the dead woman's family). The only post mortem performed was recorded extremely poorly.

There were instances of suspicious recording of events including retrospective note making and evidence of doctoring of notes. In contrast, costing of drugs used on patients was written in detail and was available in 19 of the 20 cases.

\section{DISCUSSION}

This study used an adapted version of the confidential enquiry approach to review the clinical events surrounding a sample of maternal deaths occurring in selected hospitals in two regions of Ghana. The use of confidential enquiries to investigate maternal deaths is recommended ${ }^{10,11,12}$ to learn lessons for the improvement of clinical practice to prevent pregnancy related deaths. Confidential Enquiries into Maternal Deaths (CEMD) are widely conducted in a number of countries such as the United Kingdom ${ }^{8}$, South Africa ${ }^{7}$, Malaysia ${ }^{13}$ and Egypt $^{14}$. This study described and tracked events surrounding a maternal death using a standardized assessment form.

The study revealed that fee exemption did not affect the patterns of adverse and favourable events in the provision of delivery care in the selected hospitals. This was a positive finding, as quality of care could have deteriorated due to increased utilisation without an increase in resources such as personnel and equipment ${ }^{15}$. Another possible effect of fee exemption may be that more women attend facilities earlier for delivery. Evidence was found to suggest earlier attendance by women with 
complications in our study, especially in Volta region.

Of concern were the consistently poor levels of clinical care, before and after fee exemption. The finding that eight of the 20 women had caesarean sections and these operations were done on poorly stabilized patients, contributing to their deaths, has important implications. Increasingly, the availability of comprehensive emergency obstetric care is being monitored globally by the availability of CS. CS rates in Ghana are low and according to current available statistics, only $4 \%$ of live births are delivered by $\mathrm{CS}^{2}$ Increasing this relatively low level to meet the global "standard" range of $5-15 \%$ CS rates ${ }^{16}$ can be counterproductive, with doctors performing CS proactively, but not always appropriately.

The competence and ability of doctors to deal with obstetric emergencies was assessed as requiring attention. Doctors seemed ill prepared to deal with the obstetric conditions commonly seen in district hospitals. In Ghana, one district hospital will only have on average one medical officer in attendance. This means that the medical officer covers all serious emergencies (obstetric and otherwise), and this is a situation not conducive to providing good quality emergency maternity care. Regrettably, to compound this problem of availability, doctors are not competently managing most obstetric emergencies. Then again, the severity of the complications seen may suggest a need for an extremely high level of competence usually not available in most of the facilities studied. Additionally, there were a number of cases seen which might be considered very basic emergencies that any medical officer should be able to deal with, however, even these were poorly managed. Basic resuscitation techniques (not even specific to obstetric care) appear to be either extremely poorly recorded or not done at all.

One of the inherent biases in this study is that the panel could only assess clinical practice from the case records. The quality of case records was judged to be generally poor by the panel, with a lot of missing and incomplete information. It is acknowledged that this may not reflect actual practice, but nevertheless, clinical case records have been widely used to ascertain clinical care. ${ }^{17,18,19}$ Furthermore, the quality of recording in itself can be a measure of the quality of care provided ${ }^{20,21}$ and this was demonstrated by our study through the lack of partographs, maternal death audit reports and consistently scanty notes in complicated procedures. Incomplete or lost maternal death records may also have contributed to biases.

Finally, despite the many limitations known in the health system, this study provided evidence that the health system was functioning sufficiently to offer the enabling environment for the provision of delivery care. Facilities for comprehensive emergency obstetric care, including blood transfusions, laboratory tests, drugs, equipment and consumables; as well as midwifery personnel, were in the main available. A lot more can be done to build on, and capitalize on these strengths in order to improve the delivery care provided today.

\section{CONCLUSIONS AND RECOMMEN- DATIONS}

Removing one financial barrier to accessing health services in the form of fee exemption is insufficient to reduce maternal mortality rapidly in Ghana. Even if fee exemption leads to women with complications arriving in hospital earlier, the poor care they receive in hospital causes many avoidable deaths.

Doctors' skills in obstetric care need to be improved through supportive supervision with onthe-job training and organisation of continuing medical education. Training programmes for medical officers at district level should include competencies to assess critically ill patients for "fitness for surgery", resuscitation techniques, and "forward planning" in their clinical management. The documentation of care processes needs to be improved and its importance promoted. A lack of monetary resources to purchase medical equipment, drugs and infrastructure cannot be used as an excuse for poor quality care. If not optimal, these assets are at least a part of the health system which is functioning at an acceptable level. Investment in the human resources available however, needs to be a focus.

Advocacy using the findings of this study is crucial to ensure the introduction and use of confidential enquiries by both the Ministry of Health and the Ghana Health Service for continued improvement in quality of delivery care.

\section{ACKNOWLEDGEMENT}

This work was undertaken as part of an international research programme - Immpact (Initiative for Maternal Mortality Programme Assessment). See: http://www.abdn.ac.uk/immpact, funded by 
the Bill \& Melinda Gates Foundation, the Department for International Development (DFID), the European Commission and the Unites States Agency for International Development (USAID). The funding organisations have no responsibility for the information provided or views expressed in this paper. The views expressed herein are solely those of the authors. We thank our panel members in particular for their commitment, interest and support in stimulating national interest in confidential enquiries into maternal deaths and Professor David Ofori-Adjei for comments on the initial draft of the manuscript..

\section{REFERENCES}

1. UNICEF/UNFPA/WHO. Maternal Mortality in 2000: Estimates developed by WHO, UNICEF and UNFPA Department of Reproductive Health Research, World Health Organization Geneva 2004

2. GSS and Macro Inc. Ghana Demographic and Health Survey 2003. 2004

3. Bell J, Curtis S and Alayon S. DHS Analytical Studies No 7 Trends in Delivery Care in Six Countries ORC Macro and International Research Partnership for Skilled Attendance for Everyone Calverton Maryland USA. 2003

4. IMMPACT. Implementation of free delivery policy in Ghana Policy Brief IMMPACT Project, Noguchi Memorial Institute for Medical Research Ghana and University of Aberdeen Scotland. 2005

5. Opoku SA, Kyei-Faried D, Twum S, Djan JO, Browne ENL and Bonney J. Community education to improve utilisation of emergency obstetric services in Ghana. Intl J of Obst and Gynae 1997; 59(Suppl 2): S201-207.

6. D'Ambruoso L, Abbey M, Hussein J. Please understand when I cry out in pain: women's accounts of maternity services during labour and delivery in Ghana. BMC Pub Hlth 2005; 5: 140 .

7. National Committee for Confidential Enquiries into Maternal Deaths (NCCEMD) 1998 South Africa Guidelines http://www.doh.gov.za/docs/forms/guide asse ssor.html Accessed 30th June 2005.

8. Confidential Enquiry into Maternal and Child Health (CEMACH) UK http://www.cemach.org.uk Accessed $5^{\text {th }}$ July 2005.

9. Ansong-Tornui J, Hussein J, Armar-Klemesu M, Arhinful D and Penfold S. Assessing adverse and favourable clinical factors in maternal death: Use of a confidential enquiry approach. Final draft report. Accra, Ghana: Immpact, August 2006.

10. World Health Organization. Beyond the numbers Department of Reproductive Health and Research World Health Organization Geneva. 2004

11. Cook R. The role of confidential enquiries in the reduction of maternal mortality and alternatives to this approach International Journal of Gynaecology and Obstetrics 1989; 30(1): 41-45.

12. Bouvier-Colle et al. Maternal Mortality in West Africa: rates, causes and substandard care from a prospective survey. Acta Obstet et Gynacol Scand 2001; 80(2): 113-119.

13. Suleiman AB, Mathews A, Jegasothy R, Ali R and Kandiah N. A strategy for reducing maternal mortality. Bull of the Wld Hlth Org 1999; 77: 190-193.

14. el Kady AA, Saleh S, Gadalla S, Fortney J and Bayoumi H. Obstetric deaths in Menoufia Governorate. Egypt Bri J of Obst and Gynae 1989; 96(1): 9-14.

15. Penfold S, Harrison E, Bell J. Evaluation of the free delivery policy in Ghana: Population estimates of changes in delivery service utilisation. Final draft report. Aberdeen, UK: IMMPACT, August 2006.

16. UNICEF/WHO/UNFPA. Guidelines for monitoring the availability and use of obstetric services; New York, UNICEF. 1997.

17. Miller S, Cordero M, Coleman AL, Figueroa J, Brito-Anderson S, Dabagh R, Calderon V, Caceres F, Fernandez AJ, Nunez M. Quality of care in institutionalized deliveries: The paradox of the Dominican Republic. Intl $J$ of Gynae and Obst 2003; 82(1): 89-103.

18. Adeyi O, Morrow R. Essential obstetric care: assessment and determinants of quality. Soc Sci \& Med 1997; 45(11): 1631-1639. 
19. World Health Organization. Safe Motherhood Needs Assessment WHO/RHT/MSM/96.18 Rev 1. 1996; Geneva, World Health Organization.

20. Hussein J, Bell J, Nazzar A, Abbey M, Adjei $\mathrm{S}$ and Graham WJ. The Skilled Attendance Index (SAI): Proposal for a new measure of skilled attendance at delivery. Reprod Hlth Matters 2004; 12(24): 160-170.
21. Wagaarachchi PT, Graham WJ, Penney GC, McCaw-Binns A, Yeboah Antwi K, Hall MH. Holding up a mirror: changing obstetric practice through criterion-based clinical audit in developing countries. Intl J of Gynae and Obst 2001; 74: 119-130. 